\title{
Performance of interferon- $\gamma$ release assays in the diagnosis of confirmed active tuberculosis in immunocompetent children: a new systematic review and meta-analysis
}

\author{
Patrizia Laurenti, Matteo Raponi", Chiara de Waure, Marta Marino, Walter Ricciardi and Gianfranco Damiani
}

\begin{abstract}
Background: Tuberculosis (TB) is a global public health problem, causing morbidity and mortality in adults and children. The most reliable diagnostic tools currently available are the in vivo Tuberculin Skin Test (TST) and the ex vivo Interferon- $\gamma$ release assays (IGRAs). Several clinical, radiological, and bacteriological features make the detection of active (overt disease) TB in children difficult. Although recently developed immunological assays such as QuantiFERON-TB Gold In-Tube (QFT-IT) and T-SPOT ${ }^{\circledR}$.TB are commonly used to identify active TB in adults, different evidence is required for diagnosis in children. The purpose of this study was to reassess the sensitivity and specificity of IGRAs in detecting microbiologically confirmed active TB in immunocompetent children.
\end{abstract}

Methods: A systematic review and meta-analysis of studies reporting on the diagnostic accuracy of tests for TB in immunocompetent children aged 0-18 years, with confirmation by positive M. tuberculosis cultures, were undertaken. Electronic databases were searched up to September 2015 and study quality assessment was performed using QUADAS-2.

Results: Fifteen studies were included in our meta-analysis. Results showed that there were no significant differences in sensitivity between TST (88.2 \%, 95 \% confidence interval [CI] 79.4-94.2 \%), QFT-IT (89.6\%, 95 \% Cl 79.7-95.7 \%) and T SPOT (88.5 \%, 95 \% Cl 80.4-94.1 \%). However, both QFT-IT (95.4\%, $95 \%$ Cl 93.8-96.6\%) and T-SPOT (96.8 \%, 95 \% Cl 94.2-98.5 \%) have significantly higher specificity than TST (86.3\%, $95 \%$ Cl 83.9-88.6 \%).

Conclusions: QFT-IT and T-SPOT have higher specificity than TST for detecting active TB cases in immunocompetent children.

Keywords: Active tuberculosis, Children, Meta-analysis, Diagnosis, Tuberculin skin test, IGRAs, QuantiFERON-TB Gold In-Tube, T-SPOT.TB

\section{Background}

Tuberculosis (TB) is one of the most important global public health problems and one of the major causes of adult and childhood morbidity and mortality worldwide. In 2012, there were an estimated 530,000 TB cases (bacteriologically confirmed or clinically diagnosed) among children $<15$ years of age, approximately $6 \%$ of the total number of 8.6 million cases. Among HIV-negative children, there were 74,000 TB-related deaths, approximately

\footnotetext{
* Correspondence: matteoraponi85@gmail.com

Institute of Public Health - Section of Hygiene, Università Cattolica del Sacro

Cuore, Largo Francesco Vito, 1-00168 Rome, Italy
}

$8 \%$ of the total number of 940,000 TB-related deaths among HIV-negative people [1].

In 2011, the trend in the pediatric TB notification rate showed a slight decline during the previous ten years from a peak of 5.7 in 2001. However, a number of countries, such as Bulgaria, Finland and Italy, have seen increasing trends during the same period [2]. Indeed, across Europe during the period 2000-2009, a decline or stabilization of trends was reported in high-incidence countries while low-incidence countries tended to report an increased incidence in pediatric TB. 
In 2009, only $19.2 \%$ of all childhood TB cases in Europe were confirmed by culture, a clear indication that TB diagnosis in children remains a major public health challenge [3]. Several clinical, radiological and bacteriological features (such as pauci-bacillary nature, atypical clinical signs, and a lower probability of bacteriological confirmation) make the detection of active TB in children difficult, often leading to the neglect of TB within pediatric populations [4].

As a result, the diagnosis of active disease in children often relies on a combination of contact history, clinical symptoms, and radiological findings, together with a consideration of the results of a Tuberculin Skin Test (TST) $[5,6]$.

The most reliable diagnostic tools currently available for identifying TB infection are the in vivo TST and the ex vivo interferon- $\gamma$ (IFN- $\gamma$ ) release assays (IGRAs). For almost 100 years, the TST was the main test of choice for identifying TB infection. This test measures an individual's response to a solution of Mycobacterium tuberculosis antigens and can produce false-positive and false-negative responses due to immunologic immaturity or crossreactivity with mycobacteria not in the $M$. tuberculosis complex, vaccination with Bacille Calmette-Guérin (BCG), and other undetermined causes $[7,8]$. Within the past decades, however, two new immunological assays have been developed: the QuantiFERON-TB Gold (QFT-G; Qiagen), QuantiFERON-TB Gold In-Tube (QFT-IT; Qiagen), and the

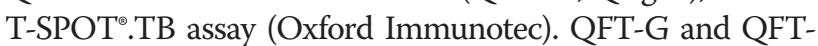
IT measure the concentration of IFN- $\gamma$ produced in whole blood by enzyme-linked immunosorbent assay (ELISA) $[8,9]$. T-SPOT measures the number of individual Mycobacterium-specific T cells secreting IFN- $\gamma$ by the enzyme-linked immunosorbent spot (ELISPOT) assay $[10,11]$.

In adults, a higher specificity of IGRAs compared with TST has been reported. The sensitivity for active TB ranges from 70 to $90 \%$ and is lower in high TB incidence settings [12-15]. Thus, IGRAs are now included by the $\mathrm{CDC}$ in the recommended diagnostic algorithm for detection of TB in adults [16]. However, caution is recommended regarding their use in children [17].

A growing number of studies have compared TST and IGRAs for the detection of $M$. tuberculosis infection, a condition that may or may not progress to clinical disease and active (overt disease) TB in children. Studies have measured sensitivity in populations with active TB and in populations exposed to TB cases $[18,19]$. Six meta-analyses [6, 20-24] have previously assessed IGRAs' sensitivity and specificity in children and reported largely different pooled estimates. These differences are due to the characteristics of the study populations and different inclusion/exclusion criteria (such as immunologic status, level of income, and concurrent infections). Two of these previous meta-analyses focused on either bacteriologically confirmed or clinically diagnosed TB cases $[6,22]$, one included contacts with TB cases in addition to the previous two categories [20], another also included cases of latent TB [21] and one [23], although providing a sub-analysis on microbiologically confirmed cases, included studies for which it was not possible to clearly identify methods used to confirm cases. In the last meta-analyses, which provided a sub-analysis including only microbiologically confirmed cases, the study population also included immunocompromised children [24]. Because of this heterogeneity, pooled estimates of sensitivity and specificity of IGRAs and TST have varied considerably. Through the use of different inclusion/exclusion criteria compared with previous studies, the aim of our study was to reassess the sensitivity and the specificity of IGRAs, QFT-IT, and T-Spot TB versus TST in the detection of bacteriologically confirmed active TB in immunocompetent children aged $0-18$ years.

\section{Methods \\ Literature retrieval}

An extensive search of the scientific literature was carried out by querying electronic databases of PubMed, EMBASE and Cochrane Library to identify articles published in English or Italian between January $1^{\text {st }} 2003$ and September $30^{\text {th }} 2015$. The following terms were used as keywords: "tuberculosis", "tuberculosis infection", or "tuberculosis disease"; "pediatrics" or "child"; "Tuberculin Test"; "Interferon-gamma Release Tests", "QuantiFERON", "ELISpot", "QFT- IT", "QFT-2G", "IFN", "Tcell assays", "T-SPOT.TB test", "ESAT-6", "CFP10", or "RD1 antigens"; "Sensitivity"; and "Specificity". Further retrieval of grey literature was conducted through consulting Google Scholar and websites of the World Health Organization (http://www.who.int/en/), Centre for Disease Control and Prevention (http://www.cdc.gov/) and the National Institute for Health and Clinical Excellence (https://www.nice.org.uk/) for relevant unpublished studies and national and international guidelines. We integrated the electronic searches with manual searches, checking the reference lists of relevant articles to identify further studies.

\section{Selection criteria}

Potential studies were selected through consideration of the title and abstract by two researchers. Disagreements were solved by a senior researcher. Full texts of eligible articles were read by two researchers to decide upon final inclusion.

The following inclusion criteria were used: only studies performed on healthy children from 0 to 18 years were considered eligible, and articles which included only adults or immunosuppressed children (such as HIV- 
positive patients) were excluded; we included only those studies focused on the sensitivity and specificity of IGRAs or TST in detecting confirmed active TB cases (considered as a child with active TB disease, confirmed by positive $M$. Tuberculosis cultures); we included only those studies including sensitivity and specificity, or where it was possible to calculate them; we included only articles that reported original data (reviews, case reports and editorials were excluded); and we included only those studies with $\geq 5$ study subjects.

\section{Quality assessment}

Two independent researchers evaluated the validity of the selected studies using the Revised Quality Assessment of Diagnostic Accuracy Studies (QUADAS-2) tool [25]. This tool assesses the risk for bias and concerns regarding applicability in four domains: patient selection, index test, reference standard, and study flow and timing. The risk of bias was evaluated through the identification of specific questions and the development of guidance on items evaluation according to QUADAS-2 recommendations. The reviewers recorded and compared the answers given to each question.

Both reviewers analysed all articles in terms of the study population, index test, reference standard, setting, diagnostic pathway, target condition, and flow diagram. For each article, researchers independently recorded a score of "low risk of bias/low concerns regarding applicability," "high risk of bias/high concerns," or "unclear" for each question. All domains with at least one negative response scored "high risk of bias" (if the negative response regarded the risk for bias) or "high concerns regarding applicability" (if the negative response regarded the applicability), while domains with no negative responses but at least one unsure response scored "unclear". Domains with no negative and no unsure responses scored "low risk of bias/low concerns". All disagreements were resolved by consensus.

\section{Data abstraction and data analysis}

Data were extracted using a standardized form including the following information: authors, year of publication, journal, country, country TB burden, study design, age of the patients, sample size, TB diagnostic tests, and TST cut-off. For each study, children representing true positives (TP), true negatives (TN), false positives (FP), and false negatives (FN) were defined by identifying microbiological culture as the reference test. With respect to TST, patients were classified as positive or negative according to the TST cut-off chosen by both the authors of each paper and to all three TST cut-offs defined by the American Academy of Paediatrics (AAP) (>5 mm, >10 mm, >15 mm). The three cut offs suggested by the AAP were applied to all patients of each study because it was not possible to classify patients in risk groups as defined by the AAP itself.

Two authors independently extracted data from the papers and corroborated their findings. Pooled sensitivity and specificity of TST, QFT-IT and T-SPOT and a $95 \%$ confidence interval $(\mathrm{CI})$ were calculated using the Der Simonian and Laird random effects model. Furthermore summary receiving operating characteristic (sROC) curves with Area Under the Curve (AUC) were obtained on the basis of the Littenberg and Moses model. MetaDisc, version 1.4 (Hospital Ramony Cajal, Madrid, Spain) [26] was used to perform the analysis. A value of 0.5 was added to all cells in studies where any cell was 0. Heterogeneity was assessed using the $\mathrm{I}^{2}$ statistic. Pooled likelihood positive and negative ratios (LR+ and LR-) were obtained to assess the informative power of the three tests.

\section{Results}

\section{Literature search}

A total of 194 articles were obtained through database searching. Among them, 169 articles were excluded after abstract reading and a further 19 excluded after review of the full text. Furthermore, after reviewing references of retrieval articles, an additional nine studies were included. A total of 15 studies [27-41] were included in the systematic review (Fig. 1).

The included studies were undertaken in 11 countries, of which four (Lithuania, China, India and Uganda) [31, 33, 37, 39, 41] had a high TB burden. Among studies considered in the analysis, six assessed both the sensitivity and specificity of IGRAs and TST [27, $30,31,33,36,39]$. The TST cut-off was set at $10 \mathrm{~mm}$ in nine studies, $5 \mathrm{~mm}$ in four studies, $15 \mathrm{~mm}$ in one study, and not defined in one. Regarding the IGRAs, five assessed both QFT-IT and T-SPOT.TB, seven only QFT-IT, and three only T-SPOT.TB. Characteristics of all included studies are given in Table 1.

\section{Quality assessment}

Results of the quality assessment are summarized in Table 2 and Fig. 2. Before disagreements were resolved, reviewers' consensus on risk for bias and concerns regarding applicability were 91.7 and $97.7 \%$, respectively. No study was considered at low risk for bias in all the domains while all studies scored low in terms of concerns regarding applicability in all domains. The study of Sun Lin et al. [33] and that of Cruz et al. [35] were considered to be the most at risk of bias; judged at high risk in each domain with the exception of the Index Test domain (Sun Lin et al.) and Reference Standard domain (Cruz et al.). The studies of Detjen et al. [27], Kampmann et al. [29], Hansted et al. [31], and Chiappini et al. [36] were considered to be less at risk for bias; judged at low risk in each domain with the exception of the Patient 


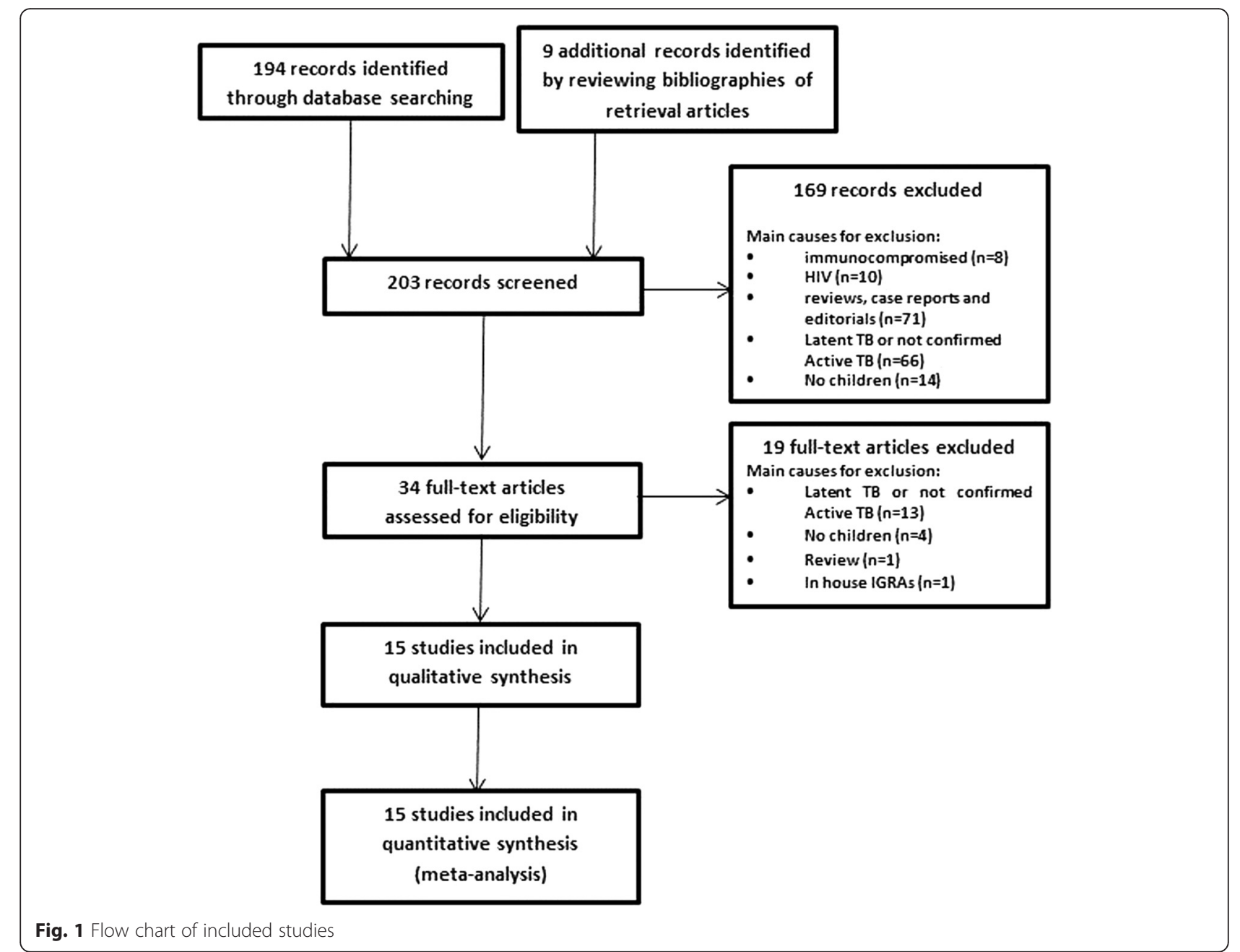

Selection domain (Detjen et al. [27], Kampmann et al. [29]) and Index Test domain (Hansted et al. [31] and Chiappini et al. [23, 36]).

In the Patient Selection domain (domain 1), five studies scored low risk for bias, one scored unclear risk (recruitment protocol not clearly stated), and nine scored high risk (sample of patients enrolled in a non-consecutive, nonrandom way or inappropriate exclusions not avoided). In the Index Test domain (domain 2), four studies had low risk for bias, in seven cases it was unclear whether the index test results were interpreted with or without knowledge of the results of the reference standard, and four scored high risk (the index test results interpreted with knowledge of the results of the reference standard). In the Reference Standard domain (domain 3), seven studies showed low risk for bias, six had unclear risk, and two were judged at high risk for bias. Indeed, in six studies, it was unclear if results of the reference standard were interpreted without knowledge of the index test, and in two cases reviewers judged that results of the reference standard were interpreted with knowledge of the index test. In the Flow and Timing domain (domain 4), seven studies scored low risk for bias, while seven were judged at high risk for bias, because not all patients recruited into the study were included in the analysis, and one scored unclear.

\section{Diagnostic performance}

TST (cut-off stated in the study), QFT-IT and T-SPOT $\mathrm{TP}, \mathrm{TN}, \mathrm{FP}$, and FN for each study are reported in Table 3.

It was only possible to define TP, TN, FP and FN according to the three TST cut off of AAP for two studies (Detjen et al. [27], Chiappini et al. [23, 36]) (Table 4).

\section{Pooled sensitivity and specificity}

\section{Accuracy of TST}

Among six studies (Detjen et al. [27], Lighter et al. [30], Hansted et al. [31], Sun Lin et al. [33], Chiappini et al. [23, 36], Jenum et al. [39]), the overall sensitivity of the TST (with respect to cut-off stated in each study) was $88.2 \%$ (95 \% CI 79.4-94.2\%). Of note, the degree of 
Table 1 Characteristics of included studies

\begin{tabular}{|c|c|c|c|c|c|c|c|c|c|c|}
\hline Author, Year & Journal & Country & Study design & $\begin{array}{l}\text { Age (years, } \\
\mathrm{m}=\text { months) }\end{array}$ & $\begin{array}{l}\text { Sample size- } \\
\text { TB cases- Controls }\end{array}$ & TB diagnostic test & Sensitivity & Specificity & TST cut-off (mm) & TB burden \\
\hline \multirow{3}{*}{$\begin{array}{l}\text { Detjen et al. } \\
\text { (2007) [27] }\end{array}$} & \multirow[t]{3}{*}{ Clin Infect Dis. } & \multirow[t]{3}{*}{ Germany } & \multirow[t]{3}{*}{ cohort study } & \multirow[t]{3}{*}{$4 \mathrm{~m}-15$} & \multirow[t]{3}{*}{2822} & TST & $1^{a}$ & $1^{\mathrm{a}}$ & \multirow[t]{3}{*}{$>10$} & \multirow[t]{3}{*}{ Low } \\
\hline & & & & & & QFT-IT & $0.93^{\mathrm{a}}$ & $1^{\mathrm{a}}$ & & \\
\hline & & & & & & T-SPOT.TB & $0.93^{\mathrm{a}}$ & $1^{\mathrm{a}}$ & & \\
\hline \multirow{3}{*}{$\begin{array}{l}\text { Domínguez et al. } \\
\text { (2008) [28] }\end{array}$} & \multirow[t]{3}{*}{ Clin Vaccine Immunol. } & \multirow[t]{3}{*}{ Spain } & \multirow[t]{3}{*}{ cohort study } & \multirow[t]{3}{*}{$\leq 18$} & \multirow[t]{3}{*}{9} & TST & $1^{\mathrm{a}}$ & - & \multirow[t]{3}{*}{$\geq 5$} & \multirow[t]{3}{*}{ Low } \\
\hline & & & & & & QFT-IT & $0.67^{\mathrm{a}}$ & - & & \\
\hline & & & & & & T-SPOT.TB & $0.86^{\mathrm{a}}$ & - & & \\
\hline \multirow{3}{*}{$\begin{array}{l}\text { Kampmann et al. } \\
\text { (2009) [29] }\end{array}$} & \multirow[t]{3}{*}{ Eur Respir J. } & \multirow[t]{3}{*}{ United Kingdom } & \multirow[t]{3}{*}{ cohort study } & \multirow[t]{3}{*}{$3 \mathrm{~m}-16$} & \multirow[t]{3}{*}{25} & TST & 0.88 & - & \multirow[t]{3}{*}{$\geq 10$} & \multirow[t]{3}{*}{ Low } \\
\hline & & & & & & QFT-IT & 0.80 & - & & \\
\hline & & & & & & T-SPOT.TB & 0.58 & - & & \\
\hline \multirow{2}{*}{$\begin{array}{l}\text { Lighter et al. } \\
\text { (2009) [30] }\end{array}$} & \multirow[t]{2}{*}{ Int J Tuberc Lung Dis. } & \multirow[t]{2}{*}{ USA } & \multirow[t]{2}{*}{ cohort study } & $\leq 17$ & 721 & TST & $0.86^{\mathrm{a}}$ & $0.86^{\mathrm{a}}$ & $\geq 10$ & Low \\
\hline & & & & & & QFT-IT & $0.86^{\mathrm{a}}$ & $1^{\mathrm{a}}$ & & \\
\hline Hansted et al. & BMC Pulm Med. & Lithuania & cohort study & $10-17$ & 2352 & TST & 1 & $0.35^{\mathrm{a}}$ & $\geq 10$ & High \\
\hline (2009) [31] & & & & & & T-SPOT.TB & 1 & $0.90^{\mathrm{a}}$ & & \\
\hline Bamford et al. & Arch Dis Child. & United Kingdom & cross-sectional study & $7.2 \mathrm{~m}-16$ & 49 & TST & 0.82 & - & $>15$ & Low \\
\hline & & & & & & T-SPOT.TB & 0.67 & - & & \\
\hline & & & & & & QFT-IT & 0.78 & - & & \\
\hline Sun Lin et al. & Chinese Medical Journal & China & case-control study & $\leq 18$ & 1851 & TST & 0.61 & 0.71 & $\geq 10$ & High \\
\hline (2UlO) [33] & & & & & & T-SPOT.TB & 0.83 & 0.94 & & \\
\hline Tsolia et al. & Pediatr Infect Dis J. & Greece & cohort study & $\leq 15$ & 13 & TST & 0.85 & - & $\geq 5$ & Low \\
\hline & & & & & & QFT-IT & $0.85^{\mathrm{a}}$ & - & & \\
\hline Cruz et al. & Pediatrics. & USA & cohort study & $\leq 18$ & 13 & TST & 0.77 & - & $\geq 5$ & Low \\
\hline & & & & & & T-SPOT.TB & 0.92 & - & & \\
\hline Chiappini et al. & PLoS One. & Italy & cohort study & $\leq 18$ & 529 & TST & $0.80^{\mathrm{a}}$ & $0.97^{\mathrm{a}}$ & $\geq 5$ & Low \\
\hline (2012) [36] & & & & & & QFT-IT & $0^{\mathrm{a}}$ & $1^{\mathrm{a}}$ & & \\
\hline Lodha et al. & Int J Tuberc Lung Dis. & India & RCT & $6 m-15$ & 128 & TST & $0.90^{\mathrm{a}}$ & - & $\geq 10$ & High \\
\hline & & & & & & QFT-IT & $0.83^{\mathrm{a}}$ & - & & \\
\hline Blandinières et al. & J Infect. & France & case-control study & $\leq 15$ & 24 & TST & $0.78^{\mathrm{a}}$ & - & $\geq 10$ & Low \\
\hline & & & & & & QFT-IT & $0.70^{\mathrm{a}}$ & - & & \\
\hline Jenum et al. & Pediatr Infect Dis J. & India & cohort study & $9 m-28 m$ & 4692 & TST & $0.75^{\mathrm{a}}$ & $0.91^{\mathrm{a}}$ & $\geq 10$ & High \\
\hline$(2014)[39]$ & & & & & & QFT-IT & $0.75^{\mathrm{a}}$ & $0.95^{\mathrm{a}}$ & & \\
\hline
\end{tabular}


Table 1 Characteristics of included studies (Continued)

\begin{tabular}{|c|c|c|c|c|c|c|c|c|c|c|}
\hline \multirow{3}{*}{$\begin{array}{l}\text { Chiappini et al. } \\
\text { (2014) [40] }\end{array}$} & \multirow[t]{3}{*}{ Pediatr Infect Dis J. } & \multirow[t]{3}{*}{ Italy } & \multirow[t]{3}{*}{ cohort study } & \multirow[t]{3}{*}{$<18$} & \multirow[t]{3}{*}{28210} & TST & $0.96^{\mathrm{a}}$ & - & \multirow[t]{3}{*}{-} & \multirow[t]{3}{*}{ Low } \\
\hline & & & & & & QFT-IT & $0.89^{\mathrm{a}}$ & $0.96^{\mathrm{a}}$ & & \\
\hline & & & & & & T-SPOT.TB & $0.78^{\mathrm{a}}$ & $0.99^{\mathrm{a}}$ & & \\
\hline \multirow[t]{2}{*}{ Petrone et al. (2015) [41] } & \multirow[t]{2}{*}{ Biomed Res Int. } & \multirow[t]{2}{*}{ Uganda } & \multirow[t]{2}{*}{ cohort study } & \multirow[t]{2}{*}{$1 m-16$} & \multirow[t]{2}{*}{7} & TST & $0.50^{\mathrm{a}}$ & - & \multirow[t]{2}{*}{$\geq 10$} & \multirow[t]{2}{*}{ High } \\
\hline & & & & & & QFT-IT & $0.60^{\mathrm{a}}$ & - & & \\
\hline
\end{tabular}

a Sensitivity and specificity were not directly reported and were calculated from available data in the study $R C T$ randomized controlled trial 
Table 2 Results of the quality assessment according to the QUADAS-2 tool

\begin{tabular}{|c|c|c|c|c|c|c|c|}
\hline \multirow[b]{2}{*}{ Study } & \multicolumn{4}{|l|}{ Risk for bias } & \multicolumn{3}{|c|}{ Applicability concerns } \\
\hline & Patient selection & Index test & Reference standard & Flow and timing & Patient selection & Index test & Reference standard \\
\hline Detjen et al. (2007) [27] & $\mathrm{H}$ & L & L & L & L & L & L \\
\hline Domínguez et al. (2008) [28] & $U$ & $\mathrm{H}$ & L & $U$ & L & L & L \\
\hline Kampmann et al. (2009) [29] & $\mathrm{H}$ & $\mathrm{L}$ & L & L & L & L & L \\
\hline Lighter et al. (2009) [30] & $\mathrm{H}$ & $U$ & $U$ & L & L & L & L \\
\hline Hansted et al. (2009) [31] & L & $\mathrm{H}$ & L & L & L & L & L \\
\hline Bamford et al. (2010) [32] & $\mathrm{H}$ & L & L & $\mathrm{H}$ & L & L & L \\
\hline Sun Lin et al. (2010) [33] & $\mathrm{H}$ & L & $\mathrm{H}$ & $\mathrm{H}$ & L & L & L \\
\hline Tsolia et al. (2010) [34] & L & $U$ & $\mathrm{H}$ & $\mathrm{H}$ & L & L & L \\
\hline Cruz et al. (2011) [35] & $\mathrm{H}$ & $\mathrm{H}$ & L & $\mathrm{H}$ & L & L & L \\
\hline Chiappini et al. (2012) [36] & L & $\mathrm{H}$ & L & L & L & L & L \\
\hline Lodha et al. (2013) [37] & $\mathrm{H}$ & $U$ & U & $L$ & $\mathrm{~L}$ & $L$ & L \\
\hline Blandinières et al. (2013) [38] & $\mathrm{H}$ & $U$ & $U$ & L & L & L & L \\
\hline Jenum et al. (2014) [39] & L & $U$ & $U$ & $\mathrm{H}$ & L & L & L \\
\hline Chiappini et al. (2014) [40] & L & U & $U$ & $\mathrm{H}$ & L & L & L \\
\hline Petrone et al. (2015) [41] & $\mathrm{H}$ & $U$ & $U$ & $\mathrm{H}$ & L & L & L \\
\hline
\end{tabular}

$H$ high risk for bias, $U$ unclear risk for bias, $L$ low risk for bias

heterogeneity of the studies was high $\left(\mathrm{I}^{2}=77.6 \%\right)$ (Fig. 3a). The pooled specificity was $86.3 \%$ (95\% CI 83.9-88.6 \%). Even here the degree of heterogeneity between the studies was high $\left(\mathrm{I}^{2}=95.2 \%\right)$ (Fig. 3b). Pooled LR+ and LR- were 5.3 and 0.2 , respectively and the AUC was 0.925. Among the two studies (Detjen et al. [27], Chiappini et al. [23, 36]) where calculation was possible, the overall sensitivity of the TST, with respect to the AAP cut-off of $>5$ mm, was $97.0 \%$ (95\% CI 84.2-99.9\%) with a heterogeneity of $74.7 \%$. The pooled specificity was $98.0 \%$ (95 \% CI 89.6-100 \%) with a heterogeneity of $12.6 \%$. Using the AAP cut-off of $>10 \mathrm{~mm}$, the overall sensitivity of the TST was $97.0 \%$ (95\% CI 84.2-99.9\%) with a heterogeneity of $74.7 \%$; the pooled specificity was $100 \%$ (95\% CI 93.0-100.0\%) with a heterogeneity of $0 \%$.
According to the AAP cut off $>15 \mathrm{~mm}$, the overall sensitivity of the TST was $60.6 \%$ (95\% CI 42.1-77.1\%) with a heterogeneity of $0 \%$; the pooled specificity was $100 \%$ (95\% CI 93.0-100.0\%) with a heterogeneity of $0 \%$.

\section{Accuracy of the QFT-IT assay}

Four studies (Detjen et al. [27], Lighter et al. [30], Chiappini et al. [40], Jenum et al. [39]) included the QFT- IT assay with a pooled sensitivity of $89.6 \%$ (95 \% CI 79.7$95.7 \%$ ) (Fig. 3c). Heterogeneity between the studies was absent $\left(\mathrm{I}^{2}=0 \%\right)$. The pooled specificity was $95.4 \%$ (95 \% CI 93.8-96.6 \%) (Fig. 3d) with slow heterogeneity $\left(\mathrm{I}^{2}=28.9 \%\right)$. Pooled LR+ and LR- were 18.2 and 0.1 , respectively and AUC was 0.988 .

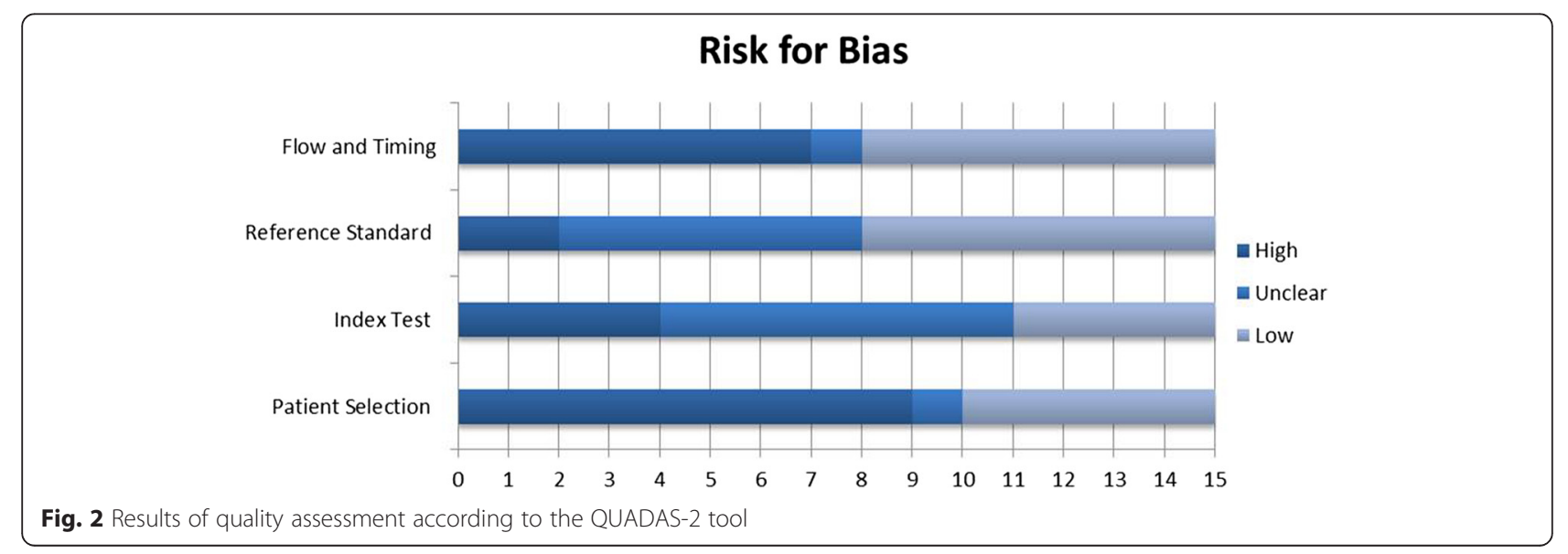


Table 3 Results of TST, QFT-IT and T-SPOT.TB

\begin{tabular}{|c|c|c|c|c|c|c|c|c|c|c|c|c|c|c|}
\hline \multirow[t]{2}{*}{ Author, Year } & \multicolumn{4}{|c|}{ TST (cut-off stated in each study) } & \multicolumn{5}{|c|}{ QFT-IT } & \multicolumn{5}{|c|}{ T-SPOT.TB } \\
\hline & $\mathrm{TP}$ & TN & $\mathrm{FP}$ & FN & $\mathrm{TP}$ & TN & FP & FN & IND & TP & $\mathrm{TN}$ & FP & FN & IND \\
\hline Detjen et al. (2007) [27] & 28 & 22 & 0 & 0 & 26 & 21 & 0 & 2 & 1 & 26 & 21 & 0 & 2 & 1 \\
\hline Domínguez et al. (2008) [28] & 9 & - & - & 0 & 6 & - & - & 3 & 0 & 6 & - & - & 1 & 2 \\
\hline Kampmann et al. (2009) [29] & 21 & - & - & 3 & 20 & - & - & 3 & 2 & 14 & - & - & 9 & 1 \\
\hline Lighter et al. (2009) [30] & 6 & 18 & 3 & 1 & 6 & 21 & 0 & 1 & 0 & / & / & / & / & / \\
\hline Hansted et al. (2009) [31] & 23 & 18 & 34 & 0 & / & / & / & / & / & 23 & 47 & 5 & 0 & 0 \\
\hline Bamford et al. (2010) [32] & 37 & - & - & 8 & 36 & - & - & 6 & 4 & 18 & - & - & 8 & 1 \\
\hline Sun Lin et al. (2010) [33] & 11 & 36 & 15 & 7 & / & / & / & / & / & 15 & 48 & 3 & 3 & 0 \\
\hline Tsolia et al. (2010) [34] & 11 & - & - & 2 & 11 & - & - & 0 & 2 & / & / & / & / & / \\
\hline Cruz et al. (2011) [35] & 10 & - & - & 3 & / & / & / & / & / & 12 & - & - & 1 & 0 \\
\hline Chiappini et al. (2012) [36] & 4 & 28 & 1 & 1 & 0 & 29 & 0 & 5 & 0 & / & / & / & / & / \\
\hline Lodha et al. (2013) [37] & 115 & - & - & 13 & 102 & - & - & 21 & 5 & / & / & / & / & / \\
\hline Blandinières et al. (2013) [38] & 18 & - & - & 5 & 16 & - & - & 7 & 0 & / & / & / & / & / \\
\hline Jenum et al. (2014) [39] & 3 & 624 & 65 & 1 & 3 & 625 & 33 & 1 & 20 & / & / & / & / & / \\
\hline Chiappini et al. (2014) [40] & 27 & - & - & 1 & 25 & 195 & 9 & 3 & 0 & 21 & 187 & 2 & 6 & 17 \\
\hline Petrone et al. (2015) [41] & 3 & - & - & 3 & 3 & - & - & 2 & 0 & / & / & / & / & / \\
\hline
\end{tabular}

$T N$ true negatives, $T P$ true positives, $F N$ false negatives, $F P$ false positives, IND indeterminate

\section{Accuracy of the T-spot assay}

For determining sensitivity of the T-SPOT, four studies (Detjen et al. [27], Hansted et al. [31], Sun Lin et al. [33], Chiappini et al. [40]) were included in the analysis. It resulted in a pooled sensitivity of $88.5 \%$ (95\% CI 80.4$94.1 \%)$ (Fig. 3e). The degree of heterogeneity was $67.1 \%$. The pooled specificity was of $96.8 \%$ (95\% CI 94.2-98.5 \%) with a heterogeneity of $71.8 \%$ (Fig. 3f). Pooled LR+ and LR- were 20.4 and 0.2 respectively and the AUC was 0.978 .

\section{Discussion}

Our study demonstrates that all the three tests were highly accurate as shown by the AUC. According to the confidence intervals of pooled estimates, there are no significant differences in sensitivity among the three methodologies assessed: TST pooled sensitivity: $88.2 \%$, 95 \% CI 79.4-94.2\%; QFT-IT pooled sensitivity: $89.6 \%$, $95 \%$ CI 79.7-95.7 \%; and T-SPOT pooled sensitivity: $88.5 \%$, $95 \%$ CI 80.4-94.1\%. However, with respect to specificity, both QFT-IT (pooled specificity: 95.4\%, $95 \%$ CI 93.8-96.6\%) and T-SPOT (pooled specificity: $96.8 \%$, $95 \%$ CI 94.2-98.5\%) performed significantly better than
TST (pooled specificity: 86.3 \%, 95 \% CI 83.9-88.6 \%). Subsequently, our findings highlight that IGRAs have a higher specificity than TST for detecting active TB cases in immunocompetent children.

For sensitivity, our results are consistent with the recent findings of Sollai et al. [24] (TST pooled sensitivity: 79 \%, 95 \% CI 75-83 \%; QFT-IT pooled sensitivity: $81 \%$, $95 \%$ CI 76-85 \%; T-SPOT pooled sensitivity: $80 \%$, $95 \%$ CI 74-84 \%). Moreover, with respect to the previously published meta-analysis, we have provided additional evidence of a higher specificity of QFT-IT and T-SPOT in bacteriologically confirmed active TB in immunocompetent children.

Since the sensitivity is equal, this improved specificity of QFT-IT and T-SPOT ensures that healthy children are not wrongly diagnosed as an active TB patient and incorrectly treated as such, exposing them to two or three drugs for at least six months. This improved specificity also reduces the negative emotional impact of a false positive result on the families of children.

The diagnosis of active TB in children is especially problematic as symptoms can be confused with those of common childhood diseases and sputum samples are

Table 4 Results of TST (according to the three TST cut off of AAP)

\begin{tabular}{|c|c|c|c|c|c|c|c|c|c|c|c|c|}
\hline \multirow[t]{2}{*}{ Author, Year } & \multicolumn{4}{|c|}{ AAP cut off $>5$} & \multicolumn{4}{|c|}{ AAP cut off $>10$} & \multicolumn{4}{|c|}{ AAP cut off $>15$} \\
\hline & $\overline{T P}$ & $\mathrm{TN}$ & FP & FN & TP & TN & FP & FN & $\overline{\mathrm{TP}}$ & TN & FP & FN \\
\hline Detjen et al. (2007) [27] & 28 & 22 & 0 & 0 & 28 & 22 & 0 & 0 & 17 & 22 & 0 & 11 \\
\hline Chiappini et al. (2012) [36] & 4 & 28 & 1 & 1 & 4 & 29 & 0 & 1 & 3 & 29 & 0 & 2 \\
\hline
\end{tabular}

$T N$ true negatives, $T P$ true positives, $F N$ false negatives, $F P$ false positives 


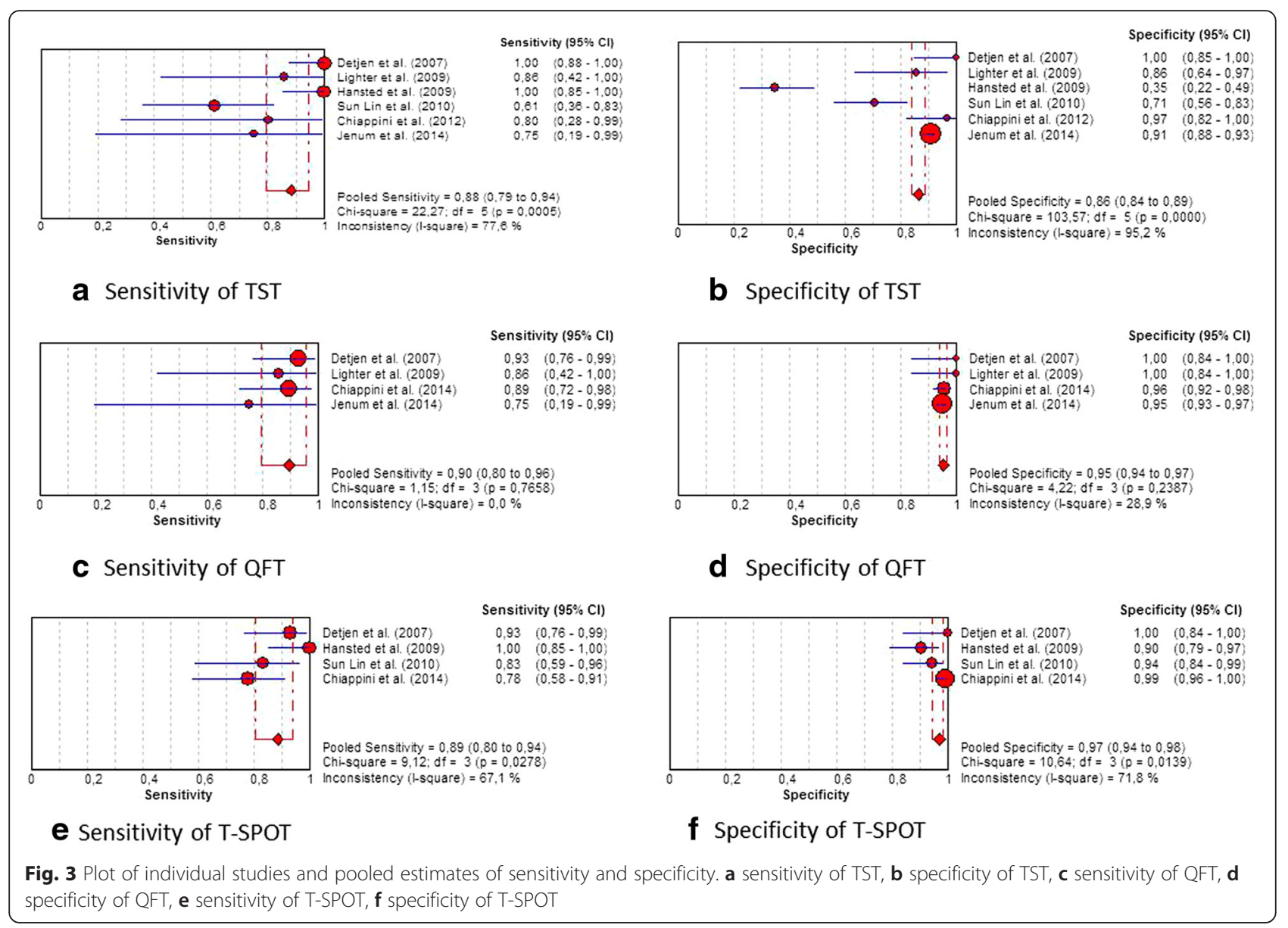

harder to obtain. For these reasons, and because of the higher specificity we have shown, the IGRAs could be used as complementary tests to support the clinical diagnosis of active $\mathrm{TB}$, in particular in the absence of bacteriological confirmation. However, it should always be considered that a negative IGRA, as well as a negative TST result, does not exclude active TB. This may be appreciated by looking at LR+ and LR- which provide an idea of the utility of the test. All the three tests we assessed have similar LR- but different LR+ (5.3 for TST, 18.2 for QFT, and 20.4 for T-SPOT). This means that if the ratio of the odds of having a negative test result in a TB patient to the odds of the same result in a healthy one is similar for the three tests, the ratio of the odds of having a positive test result in a diseased patient to the odds of the same result in a healthy child is much higher using QFT and T-SPOT instead of TST. This makes these tests useful in clinical practice as they allow clinicians to make a diagnosis of active TB [42].

The improved specificity in healthy children confirms previous evidence [12, 43, 44], encouraging the primary use of QFT-IT or T-SPOT for case finding among healthy children and young patients [45]. These children may also fail to present for TST reading as previously suggested by Lewinsohn et al. [8]. From a Public Health perspective, our results provide an opportunity to consider the use of these tests in screening too. In fact, even though all the tests we have assessed showed similar sensitivities, IGRAs do not require, unlike TST, a second visit to assess results, which may be problematic for large and specific populations [46]. Furthermore, IGRAs have been suggested to be more accurate than TST in immunocompetent people [47] and allow distinguishing individuals who have been previously vaccinated, which could represent an advantage for screening. In fact, IGRAs have already been used to screen children during the investigation of potentially exposed newborns in a Teaching Hospital [48] and the use of IGRAs in "one step" approach has been also proposed in other contexts $[49,50]$.

\section{Limitations}

Our study has a number of limitations. First, of all the studies fulfilling our inclusion criteria considered small populations. There is a small number of published studies focused on children, especially those aged $<5$ years. In fact, caution should be exercised when considering the preferential use of IGRAs in immunocompetent 
children aged $<5$ years; a warning to this effect was added to the national guidelines in the United States in a recent update [51]. Another limitation is the heterogeneity of studies, particularly concerning different and specific age groups. We did not perform a sub-analysis according to the size of TB burden (low versus high) because of the small number of studies we were able to include. For the same reason, a funnel plot was not used to investigate potential publication bias. The indeterminate rate results (inadequate interferon- $\gamma$ response to positive control (PHA/mitogen) due to anergy, excessive interferon- $\gamma$ in the negative control or, only for T-SPOT, insufficient cells, $<250,000$ cells/100 $\mu$ l) among children, which is considered an important impediment to the use of IGRAs in clinical practice for children [51], was not available in all the included studies. Further research should focus on evaluating the additional value of safety, social and ethical implications, organizational impact, and cost-effectiveness of IGRAs on the basis of a Health Technology Assessment approach.

\section{Conclusions}

QFT-IT and T-SPOT have a higher specificity than TST for detecting active TB cases in immunocompetent children, providing evidence for choices available to clinicians. These tests may be used as complementary tests to support the clinical diagnosis of active TB and may be also considered as part of public health responses.

\section{Abbreviations \\ AAP: American Academy of Pediatrics; Cl: confidence interval; ELISA: enzyme- linked immunosorbent assay; ELISPOT: enzyme-linked immunosorbent spot; FN: false negatives; FP: false positives; HIV: human immunodeficiency virus; IFN: interferon; IGRA: interferon- $\gamma$ release assay; IND: indeterminate; LR +: likelihood positive ratio; LR-: likelihood negative ratio; LTBI: latent tuberculosis infection; M. tuberculosis: Mycobacterium tuberculosis; QFT- G: QuantiFERON-TB Gold; QFT-IT: QuantiFERON-TB Gold In-Tube; QUADAS: Quality Assessment of Diagnostic Accuracy Studies: TB: tuberculosis; TN: true negatives; TP: true positives; TST: Tuberculin Skin Test; UK: United Kingdom.}

\section{Competing interests}

The authors declare that they have no competing interests.

\section{Authors' contributions}

$M R$ and MM participated in searching for the scientific literature, selection and quality assessment of articles, data collection, and data analysis. CdW performed the meta-analysis. PL, GD and WR drafted the Discussion and conclusions and supervised the work. All authors participated in the study design and in writing of the manuscript. All authors approved the final manuscript.

Received: 23 December 2014 Accepted: 10 March 2016 Published online: 18 March 2016

\section{References}

1. World Health Organization. WHO Global tuberculosis report 2013. 2013. [http://www.who.int/tb/publications/global_report/en/]. Accessed 15 Mar 2016.

2. European Centre for Disease Prevention and Control/WHO Regional Office for Europe. Tuberculosis surveillance and monitoring in Europe 2013. Stockholm: European Centre for Disease Prevention and Control; 2013.
3. Sandgren A, Hollo V, Quinten C, Manissero D. Childhood tuberculosis in the European Union/European Economic Area, 2000 to 2009. Euro Surveill. 2011; 16(12).

4. Rigouts L. Clinical practice: diagnosis of childhood tuberculosis. Eur J Pediatr. 2009;168(11):1285-90.

5. Hesseling AC, Schaaf HS, Gie RP, Starke JR, Beyers N. A critical review of diagnostic approaches used in the diagnosis of childhood tuberculosis. Int J Tuberc Lung Dis. 2002;6:1038-45.

6. Mandalakas AM, Detjen AK, Hesseling AC, Benedetti A, Menzies D. Interferon-gamma release assays and childhood tuberculosis: systematic review and meta-analysis. Int J Tuberc Lung Dis. 2011;15(8):1018-32.

7. Trajman A, Steffen RE, Menzies D. Interferon-gamma release assays versus tuberculin skin testing for the diagnosis of latent tuberculosis infection: an overview of the evidence. Pulm Med. 2013;2013:601737.

8. Lewinsohn DA, Lobato MN, Jereb JA. Interferon-gamma release assays: new diagnostic tests for Mycobacterium tuberculosis infection, and their use in children. Curr Opin Pediatr. 2010;22(1):71-6.

9. Inc C. Clinicians guide to QuantiFERON-TB. 2001 [http://www.accessdata.fda. gov/cdrh_docs/pdf/P010033c.pdf]. Accessed 15 Mar 2016.

10. Oxford Immunotec. T-SPOT.TB Package insert. 2012. [http://www.tspot.com/ wp-content/uploads/2012/01/PI-TB-US-v5.pdf]. Accessed 15 Mar 2016.

11. Lalvani A, Millington KA. T cell-based diagnosis of childhood tuberculosis infection. Curr Opin Infect Dis. 2007:20(3):264-71.

12. Diel R, Loddenkemper R, Nienhaus A. Evidence based comparison of commercial interferon-gamma release assays for detecting active tuberculosis- a meta-analysis. Chest. 2010;137:952-68.

13. Metcalfe JZ, Everett CK, Steingart KR, Cattamanchi A, Huang L, Hopewell PC, Pai M. Interferon- $\gamma$ release assays for active pulmonary tuberculosis diagnosis in adults in low- and middle-income countries: systematic review and meta-analysis. J Infect Dis. 2011;204 Suppl 4:S1120-9.

14. Pai M, Zewerling A, Menzies D. Systematic review: T-cell-based assays for the diagnosis of latent tuberculosis infection: an update. Ann Intern Med. 2008;149:177-84.

15. Dheda K, van Zyl SR, Badri M, Pai M. T-cell interferon- $\gamma$ release assays for the rapid immunodiagnosis of tuberculosis: clinical utility in high-burden vs. low-burden settings. Curr Opin Pulm Med. 2009:15:188-200.

16. Mazurek GH, Jereb JA, Vernon AN, LoBue PA, Castro KG. Provisional guidelines for use of interferon gamma release assays (IGRAs) to detect Mycobacterium tuberculosis infection in the United States. Atlanta: National TB Meeting; 2009 [https://www.signup4.net/Upload/NTCA10A/2004221E/ 2009NTC.PPT\%20Presentation.Mazurek.pdf]. Accessed 15 Mar 2016.

17. National Institute for Health and Clinical Excellence. Clinical diagnosis and management of tuberculosis, and measures for its prevention and control. London: National Institute for Health and Clinical Excellence; 2011 [http:// guidance.nice.org.uk/CG117]. Accessed 15 Mar 2016.

18. Hesseling AC, Mandalakas AM, Kirchner HL, Chegou NN, Marais BJ, Stanley K, Zhu X, Black G, Beyers N, Walzl G. Highly discordant T-cell responses in individuals with recent household tuberculosis exposure. Thorax. 2008;64: 840-6.

19. Lienhardt C, Sillah J, Fielding K, Donkor S, Manneh K, Warndorff D, Bennett S. McAdam K. Risk factors for tuberculosis infection in children in contact with infectious tuberculosis cases in the Gambia, West Africa. Pediatrics. 2003:111:e608-14.

20. Menzies D, Madhukar P, Comstock G. Meta-analysis: new tests for the diagnosis of latent tuberculosis infection: areas of uncertainty and recommendations for research. Ann Intern Med. 2007;146(5):340-54.

21. Machingaidze S, Wiysonge CS, Gonzalez-Angulo Y, Hatherill M, Moyo S, Hanekom W, Mahomed $\mathrm{H}$. The utility of an interferon gamma release assay for diagnosis of latent tuberculosis infection and disease in children: a systematic review and meta-analysis. Pediatr Infect Dis J. 2011;30:694-700.

22. Sun $L$, Xiao J, Miao Q, Feng W, Wu X, Yin Q, et al. Interferon gamma release assay in diagnosis of pediatric tuberculosis: a meta-analysis. FEMS Immunol Med Microbiol. 201 1;63:165-73.

23. Chiappini E, Accetta G, Bonsignori F, Boddi V, Galli L, Biggeri A, De Martino $M$. Interferon- $\gamma$ release assays for the diagnosis of Mycobacterium tuberculosis infection in children: a systematic review and meta-analysis. Int J Immunopathol Pharmacol. 2012;25:557-64.

24. Sollai S, Galli L, de Martino M, Chiappini E. Systematic review and meta-analysis on the utility of Interferon-gamma release assays for the diagnosis of Mycobacterium tuberculosis infection in children: a 2013 update. BMC Infect Dis. 2014;14 Suppl 1:S6. 
25. Whiting PF, Rutjes AW, Westwood ME, Mallett S, Deeks JJ, Reitsma JB, Leeflang MM, Sterne JA, Bossuyt PM. QUADAS-2: a revised tool for the quality assessment of diagnostic accuracy studies. Ann Intern Med. 2011; 155:529-36.

26. Zamora J, Abraira V, Muriel A, Khan K, Coomarasamy A. Meta-DiSc: a software for meta-analysis of test accuracy data. BMC Med Res Methodol. 2006;6:31.

27. Detjen AK, Keil T, Roll S, Hauer B, Mauch H, Wahn U, Magdorf K. Interferon-gamma release assays improve the diagnosis of tuberculosis and nontuberculous mycobacterial disease in children in a country with a low incidence of tuberculosis. Clin Infect Dis. 2007;45(3):322-8.

28. Domínguez J, Ruiz-Manzano J, De Souza-Galvão M, Latorre I, Milà C, Blanco S, Jiménez MA, Prat C, Lacoma A, Altet N, Ausina V. Comparison of two commercially available gamma interferon blood tests for immunodiagnosis of tuberculosis. Clin Vaccine Immunol. 2008;15(1):168-71.

29. Kampmann B, Whittaker E, Williams A, Walters S, Gordon A, Martinez-Alier N, Williams B, Crook AM, Hutton AM, Anderson ST. Interferon-gamma release assays do not identify more children with active tuberculosis than the tuberculin skin test. Eur Respir J. 2009:33(6):1374-82.

30. Lighter J, Rigaud M, Huie M, Peng CH, Pollack H. Chemokine IP-10: an adjunct marker for latent tuberculosis infection in children. Int J Tuberc Lung Dis. 2009;13(6):731-6.

31. Hansted E, Andriuskeviciene A, Sakalauskas R, Kevalas R, Sitkauskiene B. Tcell-based diagnosis of tuberculosis infection in children in Lithuania: a country of high incidence despite a high coverage with bacille CalmetteGuerin vaccination. BMC Pulm Med. 2009;9:41.

32. Bamford AR, Crook AM, Clark JE, Nademi Z, Dixon G, Paton JY, Riddell A, Drobniewski F, Riordan A, Anderson ST, Williams A, Walters S, Kampmann B. Comparison of interferon-gamma release assays and tuberculin skin test in predicting active tuberculosis (TB) in children in the UK: a paediatric TB network study. Arch Dis Child. 2010;95(3):180-6.

33. Sun L, Yan HM, Hu YH, Jiao WW, Gu Y, Xiao J, Li HM, Jiao AX, Guo YJ, Shen $A D$. IFN- $\gamma$ release assay: a diagnostic assistance tool of tuberculin skin test in pediatric tuberculosis in China. Chin Med J (Engl). 2010;123(20):2786-91.

34. Tsolia MN, Mavrikou M, Critselis E, Papadopoulos NG, Makrinioti H, Spyridis NP, Metsou F, Tsagaraki M, Koulouri M, Kafetzis DA. Whole blood interferon- $\gamma$ release assay is a useful tool for the diagnosis of tuberculosis infection particularly among Bacille Calmette Guèrin-vaccinated children. Pediatr Infect Dis J. 2010;29(12):1137-40.

35. Cruz AT, Geltemeyer AM, Starke JR, Flores JA, Graviss EA, Smith KC Comparing the tuberculin skin test and T-SPOT.TB blood test in children. Pediatrics. 2011;127(1):e31-8.

36. Chiappini E, Della Bella C, Bonsignori F, Sollai S, Amedei A, Galli L, Niccolai E, Del Prete G, Singh M, D'Elios MM, de Martino M. Potential role of M. tuberculosis specific IFN- $\gamma$ and IL-2 ELISPOT assays in discriminating children with active or latent tuberculosis. PLoS One. 2012;7(9), e46041.

37. Lodha R, Mukherjee A, Saini D, Saini S, Singh V, Singh S, Grewal HM, Kabra SK; Delhi TB Study Group. Role of the QuantiFERON-TB Gold In-Tube test in the diagnosis of intrathoracic childhood tuberculosis. Int J Tuberc Lung Dis. 2013;17(11):1383-8.

38. Blandinières A, de Lauzanne A, Guérin-El Khourouj V, Gourgouillon N, See $H_{\text {, }}$ Pédron B, et al. QuantiFERON to diagnose infection by Mycobacterium tuberculosis: performance in infants and older children. J Infect. 2013;67(5): 391-8.

39. Jenum S, Selvam S, Mahelai D, Jesuraj N, Cárdenas V, Kenneth J, Hesseling AC, Doherty TM, Vaz M, Grewal HM. Influence of age and nutritional status on the performance of the tuberculin skin test and QuantiFERON-TB gold in-tube in young children evaluated for tuberculosis in Southern India. Pediatr Infect Dis J. 2014;33(10):e260-9.

40. Chiappini E, Bonsignori F, Mazzantini R, Sollai S, Venturini E, Mangone G, Cortimiglia M, Olivito B, Azzari C, Galli L, de Martino M. Interferon-gamma release assay sensitivity in children younger than 5 years is insufficient to replace the use of tuberculin skin test in western countries. Pediatr Infect Dis J. 2014;33(12):1291-3.

41. Petrone L, Cannas A, Aloi F, Nsubuga M, Sserumkuma J, Nazziwa RA, Jugheli L, Lukindo T, Girardi E, Reither K, Goletti D. Blood or urine IP-10 cannot discriminate between active tuberculosis and respiratory diseases different from tuberculosis in children. Biomed Res Int. 2015;2015:589471.

42. Starke JR, Committee On Infectious Diseases. Interferon- $\gamma$ release assays for diagnosis of tuberculosis infection and disease in children. Pediatrics. 2014 134(6):e1763-73.
43. Soysal A, Türel O, Toprak D, Bakir M. Comparison of positive tuberculin skin test with an interferon-gamma-based assay in unexposed children. Jpn J Infect Dis. 2008;61(3):192-5.

44. Taylor RE, Cant AJ, Clark JE. Potential effect of NICE tuberculosis guidelines on paediatric tuberculosis screening. Arch Dis Child. 2008;93(3):200-3.

45. Mazurek GH, Jereb J, Lobue P, lademarco MF, Metchock B, Vernon A. Guidelines for using the QuantiFERON${ }^{\oplus}$-TB Gold test for detecting Mycobacterium tuberculosis infection, United States. MMWR Recomm Rep. 2005:54(RR-15):49-55.

46. Centers for Disease Control and Prevention. Tuberculosis (TB), Fact sheets. Testing and diagnosis. Interferon-gamma release assays (IGRAs) - blood tests for TB infection. 2012 [http://www.cdc.gov/tb/publications/factsheets/ testing/IGRA.pdf]. Accessed 15 Mar 2016.

47. De Keyser E, De Keyser F, De Baets F. Tuberculin skin test versus interferongamma release assays for the diagnosis of tuberculosis infection. Acta Clin Belg. 2014;69(5):358-66.

48. Borgia P, Cambieri A, Chini F, Coltella L, Delogu G, Di Rosa E, Fadda G, Giorgi Rossi P, Girardi E, Goletti D, Guasticchi G, Morrone A, Pezzotti P, Romagnoli C, Sacerdote M, Russo C, Villani A, Zarelli L. Suspected transmission of tuberculosis in a maternity ward from a smear-positive nurse: preliminary results of clinical evaluations and testing of neonates potentially exposed, Rome, Italy, 1 January to 28 July 2011. Euro Surveill. $2011 ; 16(40)$

49. Amicosante M, Ciccozzi M, Markova R. Rational use of immunodiagnostic tools for tuberculosis infection: guidelines and cost effectiveness studies. New Microbiol. 2010:33(2):93-107.

50. Giri P, Basu S, Sargeant T, Rimmer A, Pirzada O, Adisesh A. Pre-placement screening for tuberculosis in healthcare workers. Occup Med (Lond). 2014; 64(7):524-9.

51. Mazurek GH, Jereb J, Vernon A, LoBue P, Goldberg S, Castro K, IGRA Expert Committee; Centers for Disease Control and Prevention (CDC). Updated guidelines for using Interferon Gamma Release Assays to detect Mycobacterium tuberculosis infection - United States, 2010. MMWR Recomm Rep. 2010;59(RR-5):1-25.

\section{Submit your next manuscript to BioMed Central and we will help you at every step:}

- We accept pre-submission inquiries

- Our selector tool helps you to find the most relevant journal

- We provide round the clock customer support

- Convenient online submission

- Thorough peer review

- Inclusion in PubMed and all major indexing services

- Maximum visibility for your research

Submit your manuscript at www.biomedcentral.com/submit 